\title{
STRUCTURAL MODELLING INVESTIGATION OF RECIPROCALLY SUPPORTED ELEMENT LATTICE HONEYCOMB DOMES
}

\author{
J.P. RIZZUTO \\ School of Computing \& Engineering, University of West London, United Kingdom.
}

\begin{abstract}
Reciprocally supported element (RSE) lattice honeycomb dome structures have the ability to support considerable loading via their composition of interconnected closed circuits of elements. Distinctively, these dome structures use only three elements in each circuit. To understand the structural behaviour of these RSE lattice domes, a structural modelling investigation was carried out. Global linear elastic analysis was considered where the behaviour of the structure under the application of loading on selected elements was monitored. The aim of the modelling was to investigate the influencing factors to monitor for model calibration as well as to compare predicted structural behaviour output with future monitored behaviour in laboratory experiments involving the manufacture and construction of an RSE lattice honeycomb dome structure. The creation of the selected RSE honeycomb lattice structures together with the structural modelling findings are presented and discussed. Predicted displacements and stresses were compared under varying boundary support conditions. The von Mises ductile material failure criterion showing the onset of local yielding is considered.

Keywords: honeycomb domes, reciprocally supported elements, space structures, structural behaviour, structural modelling.
\end{abstract}

\section{INTRODUCTION}

Reciprocally supported element (RSE) lattice honeycomb dome structures have the ability to support considerable loading via their composition of interconnected closed circuits of elements. Distinctively, these dome structures require only three elements in each module circuit. Configuration processing, therefore, can be greatly simplified when compared to other RSE forms [1,2].

The aim of this study was to compare predicted structural modelling behaviour with future monitored behaviour in the laboratory. The first part of this study, presented here, was the global structural analysis modelling. The second and third parts involves finite element analysis, manufacture and construction, and monitored behaviour in the laboratory. Experimental output would aid calibration of the predicted analysis output to be carried out.

\section{DIAMATIC HONEYCOMB DOMES}

Diamatic domes are another family of lattice domes along with the ribbed, Schwedler and Lamella type. Diamatic domes are frequently used in practice due to the avoidance of element cluttering near the crown [3]. There are many diamatic patterns available including ones with a honeycomb configuration. When considering RSE transformation, this type is very convenient as there are only the minimum required three elements forming each closed module circuit [1-3]. 


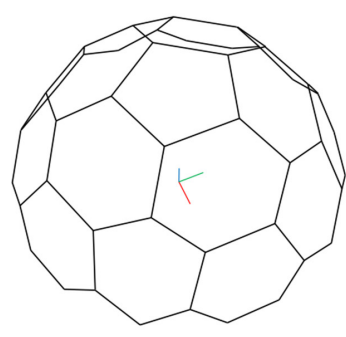

(a)

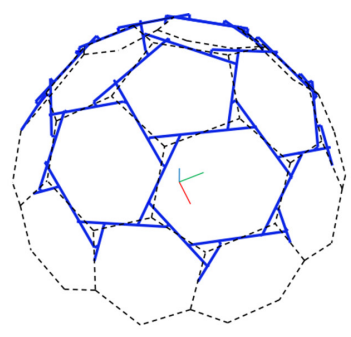

(b)

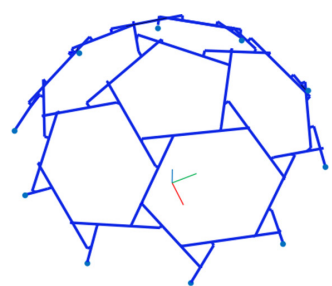

(c)

Figure 1: Perspective views of (a) basic, (b) rotation method transformation and (c) RSE honeycomb dome using initial rotation angle of 15 degrees.

\subsection{RSE Transformation}

Formian was used to create basic elemental lattice honeycomb domes to be considered for transformation into equivalent RSE domes [3]. A selected dome configuration was dimensioned in anticipation of fabrication requirements. Sweep angles considered were within a range of $30^{\circ}$ to $70^{\circ}$ where an increase in the sweep angle increases the rise at the dome crown.

A sweep angle of $60^{\circ}$ was taken as the most suitable for this study. Figure 1a shows a view of the basic dome of initial diameter of $3.2 \mathrm{~m}$ selected for detailed investigation. This was imported from Formian [3] into Rhinoceros [4] to carry out the RSE transformation. Figures $1 b$ and $c$ illustrate the transformed honeycomb lattice dome into an RSE structure using the rotation method $[1,5]$. An initial rotational angle of $15^{\circ}$ was used to generate the initial eccentricities.

\subsubsection{Transformation optimisation}

It was anticipated that a dome would be constructed from cylindrical $48.3 \mathrm{~mm}$ diameter Circular Hollow Section (CHS) tubes, bolted together with $12 \mathrm{~mm}$ diameter bolts in $13.0 \mathrm{~mm}$ diameter clearance (oversized) holes, and utilising saddleback washers with a minimum thickness of $0.85 \mathrm{~mm}$ for accurate seating and location.

The modified rotation method was used to achieve a $50 \mathrm{~mm}$ target eccentricity [5]. To keep the optimisation time to a minimum, the accuracy of the final eccentricity values obtained was considered to be sufficient at $50 \mathrm{~mm},(+) 2.5 \mathrm{~mm}$ or $(-) 0.5 \mathrm{~mm}$, as small dimensional differences could be made up with (parallel faced flat washer) shims [6]. The final RSE dome span and rise was determined as 3,066 mm and $894 \mathrm{~mm}$, respectively. See Fig. 2 and Table 1.

\section{STRUCTURAL MODELLING}

The dome structure was analysed considering varying boundary support conditions and loading regimes using Oasys General Structural Analysis, GSA, software with 3-dimensional and finite element capabilities [7].

\subsection{Boundary support conditions}

It was anticipated that it would be difficult to model the experimental support conditions and, therefore, a range of possible conditions were considered. It was assumed that, (i) some of the 


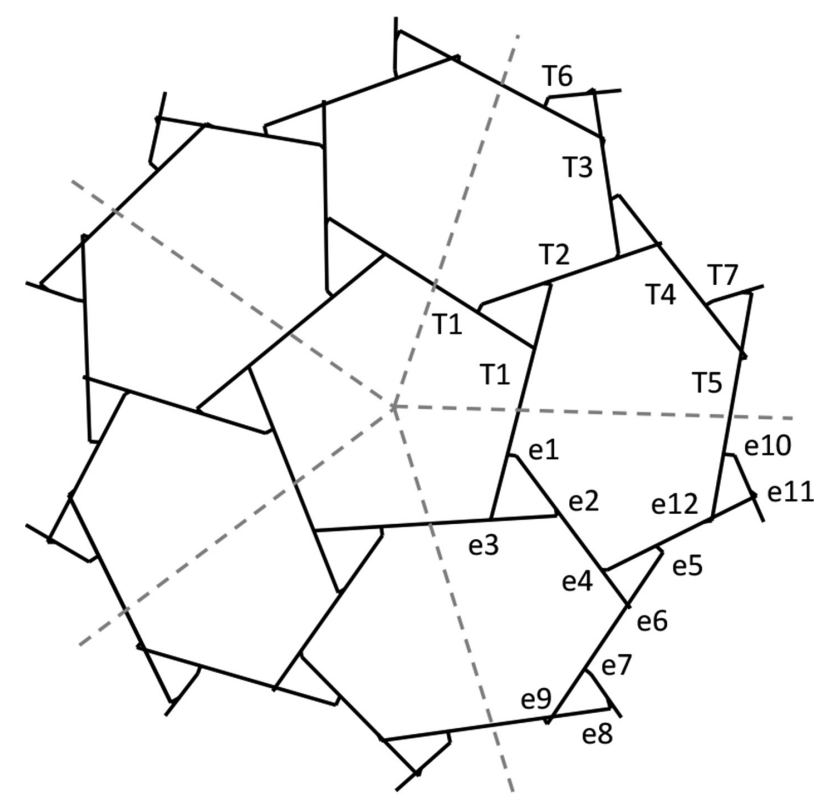

Figure 2: RSE dome plan (sector symmetry indicated by dotted lines). Eccentricity, e (bolted connections) locations and elements types, T1 - T7 identical in all sectors.

Table 1: Initial and optimised eccentricity, e values (all in $\mathrm{mm}$ ) shown in Fig. 2.

\begin{tabular}{|c|c|c|c|c|c|c|c|}
\hline $\begin{array}{l}\text { Target e } \\
\text { value } \\
50.0\end{array}$ & $\begin{array}{l}15^{\circ} \text { Rotation } \\
\text { Initial e } \\
\text { value }\end{array}$ & $\begin{array}{l}\text { Optimised } \\
50(+2.5 /-0.5) \\
\text { e value }\end{array}$ & $\begin{array}{l}\text { Spacer } \\
\text { (shim) } \\
\text { thickness }\end{array}$ & $\begin{array}{l}\text { Target e } \\
\text { value } \\
50.0\end{array}$ & $\begin{array}{l}15^{\circ} \text { Rotation } \\
\text { Initial e } \\
\text { value }\end{array}$ & $\begin{array}{l}\text { Optimised } \\
50(+2.5 /- \\
0.5) \text { e value }\end{array}$ & $\begin{array}{l}\text { Spacer } \\
\text { (shim) } \\
\text { thickness }\end{array}$ \\
\hline e1 & 57.5 & 51.2 & 1.0 & e7 & 37.3 & 50.8 & 1.0 \\
\hline e2 & 55.3 & 50.5 & 1.0 & e8 & 46.9 & 50.1 & 0 \\
\hline e3 & 51.2 & 52.3 & 2.0 & e9 & 56.2 & 50.9 & 1.0 \\
\hline e4 & 38.3 & 49.5 & 0 & e10 & 47.8 & 50.7 & 1.0 \\
\hline e5 & 45.3 & 50.7 & 1.0 & e11 & 39.0 & 50.5 & 1.0 \\
\hline e6 & 37.0 & 49.7 & 0 & e12 & 53.7 & 49.6 & 0 \\
\hline
\end{tabular}

support legs may be free to move laterally as they would not be mechanically fixed in position, (ii) some minor geometric self-adjustments would take place within the dome structure when initial loading commenced $[1,6]$. Thus, the support conditions anticipated included:

Condition 1 - All inclined boundary elements in contact with the support plane taken as pinned. Condition 2 - Sliding of the boundary element support nodes in the $\mathrm{x}$ and $\mathrm{y}$ axes directions occurring due to the static frictional resistance being exceeded. The criteria used to determine sliding for each support leg was: Sliding force, $\mathrm{P}=\left[\left(\mathrm{Fx}^{2}+\mathrm{Fy}^{2}\right)^{0.5}\right]>$ Frictional resistance, $\mathrm{F}^{\prime}=[\mu . \mathrm{Fz}]$.

Where Fx and Fy are the $\mathrm{x}$ - and $\mathrm{y}$-axis horizontal direction reaction force components obtained from GSA analysis output, $\mathrm{F}^{\prime}$ is the friction force opposing motion (taken as being 
independent of area), $\mathrm{Fz}$ is the normal reaction force (from the total weight of the structure) acting on the surfaces in contact and $\mu$ is the coefficient of static friction [8].

Table 2 illustrates the sequence of predicted sliding of the support nodes. Values of $\mu$ from 0.9 to 1.2 indicate the viable range of analysis models with sliding supports.

Condition 3 - All inclined boundary support elements considered as having axial and horizontal spring stiffnesses. The axial stiffnesses were determined using $\mathrm{k}=\mathrm{AE} / \mathrm{L}$ where $\mathrm{A}$ is the area, $\mathrm{E}$ is the elastic modulus and L equals the support leg length.

The horizontal spring stiffnesses were determined in stages. Firstly, an initial elastic analysis assuming that all support nodes were pinned under a $1.0 \mathrm{kN}$ total applied loading was carried out. Other analyses assumed the same loading conditions, but with all nodes but two, or three, or each node in turn being on roller supports, with Fz direction restrained only. These gave the horizontal reaction forces, Fx and Fy and the Ux and Uy displacements required.

The horizontal spring stiffnesses, $\mathrm{kx}$ and ky were determined assuming simple linear springs from $\delta=\mathrm{F} / \mathrm{k}$ where $\delta$ was the displacement, $\mathrm{F}$ the reaction force and $\mathrm{k}$, the spring stiffness. See Table 3.

Table 2: Summary of predicted boundary support nodes sliding (Y). See Fig. 5 for node locations.

\section{Predicted boundary support nodes sliding (Y)}

(Self-weight of structure + loading beam) with total point load value of $(+) 2 \times 4 \mathrm{kN}$ :

\begin{tabular}{|c|c|c|c|c|c|c|c|c|}
\hline & & $\mu(0.7)$ & $\mu(0.8)$ & $\mu(0.9)$ & $\mu(1.0)$ & $\mu(1.1)$ & $\mu(1.2)$ & $\mu(1.3)$ \\
\hline \multirow{10}{*}{ 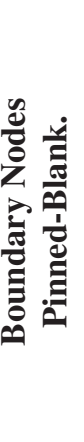 } & n. 242 & $\mathrm{Y}$ & $\mathrm{Y}$ & $\mathrm{Y}$ & $\mathrm{Y}$ & Y & Y & \\
\hline & n. 246 & $\mathrm{Y}$ & $\mathrm{Y}$ & & & & & \\
\hline & n. 252 & $\mathrm{Y}$ & $\mathrm{Y}$ & $\mathrm{Y}$ & & & & \\
\hline & n. 256 & $\mathrm{Y}$ & $\mathrm{Y}$ & Y & Y & Y & & \\
\hline & n. 262 & $\mathrm{Y}$ & $\mathrm{Y}$ & & & & & \\
\hline & n.266 & $\mathrm{Y}$ & $\mathrm{Y}$ & $\mathrm{Y}$ & $\mathrm{Y}$ & & & \\
\hline & n. 274 & $\mathrm{Y}$ & & & & & & \\
\hline & n. 280 & $\mathrm{Y}$ & $\mathrm{Y}$ & $\mathrm{Y}$ & $\mathrm{Y}$ & $\mathrm{Y}$ & & \\
\hline & n. 284 & $\mathrm{Y}$ & $\mathrm{Y}$ & $\mathrm{Y}$ & & & & \\
\hline & n. 288 & $\mathrm{Y}$ & $\mathrm{Y}$ & $\mathrm{Y}$ & $\mathrm{Y}$ & Y & & \\
\hline
\end{tabular}

Table 3: Sample of support nodes horizontal spring stiffnesses, kx and ky. All nodes restrained in z-direction. See Fig. 5 for node locations.

\begin{tabular}{lllllllllll}
\hline & \multicolumn{10}{c}{ Boundary Nodes } \\
\cline { 2 - 11 } & $\mathbf{n . 2 4 2}$ & $\mathbf{n . 2 4 6}$ & $\mathbf{n . 2 5 2}$ & $\mathbf{n . 2 5 6}$ & $\mathbf{n . 2 7 4}$ & $\mathbf{n . 2 6 6}$ & $\mathbf{n . 2 8 0}$ & $\mathbf{n . 2 8 4}$ & $\mathbf{n . 2 8 8}$ \\
\hline $\mathbf{K x}[\mathrm{kN} / \mathrm{m}]$ & -70.7 & -201.6 & -160.9 & -90.9 & Pin & -116.0 & -212.9 & -155.7 & -137.0 \\
$\mathbf{K y}[\mathrm{kN} / \mathrm{m}]$ & -73.7 & -94.6 & 188.0 & -44.3 & Pin & -658.4 & -225.8 & -105.8 & -79.6 \\
\hline
\end{tabular}




\subsection{Connections between CHS elements}

The connections were modelled using the optimised eccentricity, e values between the CHS centroidal axes $[9,10]$. To allow for the anticipated full bolt length of $125 \mathrm{~mm}$ self-weight, two GSA 'beam' elements types were used. The first modelled the $12 \mathrm{~mm}$ bolt diameter representing e. The second modelled an equivalent length of $40 \mathrm{~mm}$ and diameter of $15 \mathrm{~mm}$ which was represented by volume, weights of the bolt, nuts and saddleback washers either side of the eccentricity length. See Fig. 3a-c.

Figure $3 b$ and $c$ show the GSA connection models used. Connection model 1 in Fig. $3 b$ was not complex to generate for analysis and did not require knowledge of connection element spring stiffnesses. The fixity however resulted in apparent unrepresentative high stresses in the bolts [11].

To avoid these high stresses, GSA 'spring' elements were used to represent the connection as shown in Fig. 3c. Springs can be either lateral or rotational as defined by the spring property. Releases are not permitted for springs in GSA as they cannot have both lateral and rotational properties [7]. The two spring properties required were determined by generating finite element partial models using GSA 'Quad4' 2D shell elements of the connection between the CHSs as shown in Fig. 4. A target eccentricity of $50 \mathrm{~mm}$ and angle of 45 degrees between the CHSs was used to represent the range of bolted connection optimised rotation angles. The properties determined were $\mathrm{k}_{\mathrm{R}}=\mathrm{M} / \theta$ (for the rotational) and $\mathrm{k}_{\mathrm{T}}=\mathrm{F} / \delta$ (for the translational) stiffnesses. The stiffness values were averaged for the anticipated tube monitoring points. This is the subject of further detailed study. Table 4 shows typical translational and rotational spring stiffness values used in connection model 2 shown in Fig. 3c.

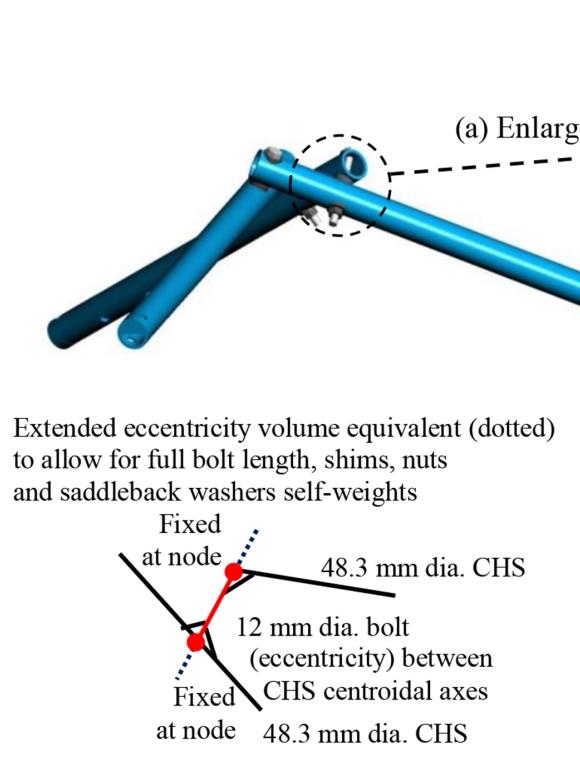

(b) Connection model 1
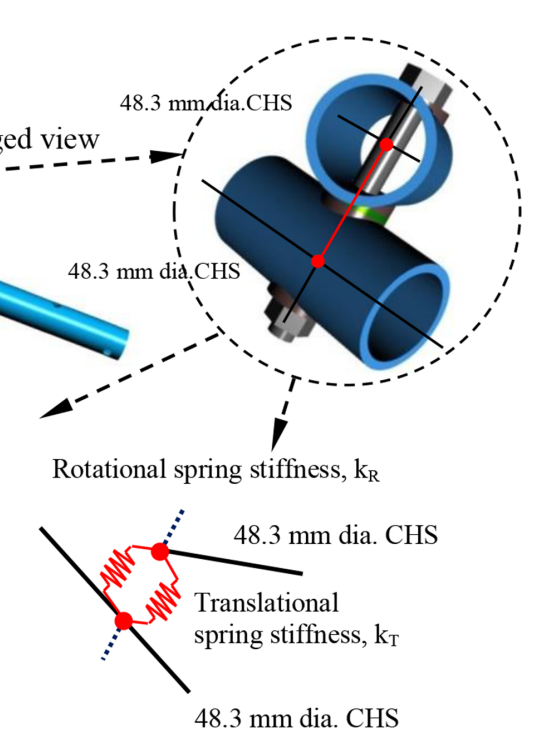

(c) Connection model 2

Figure 3: (a) Typical bolted connection detail of an RSE module, (b) and (c) GSA analysis connection models 1 and 2 considered. 


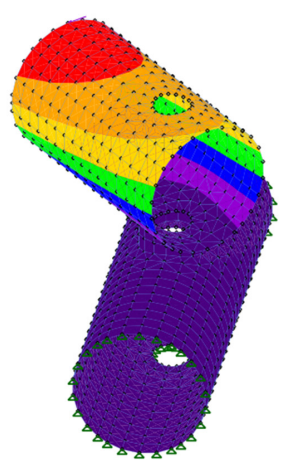

(a)
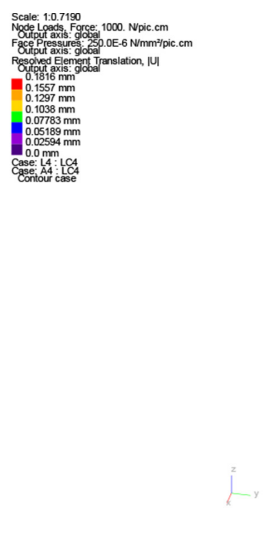

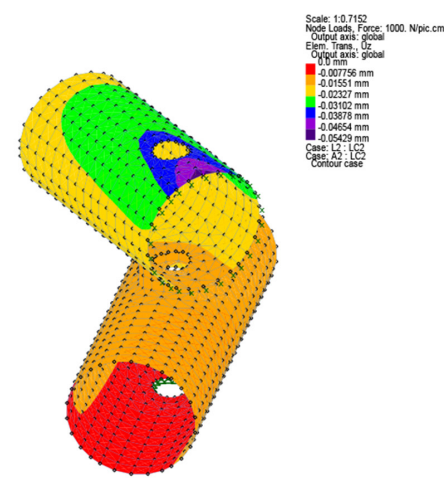

(b)

Figure 4: GSA representative FEA connection models used to determine (a) rotational, $\mathrm{k}_{\mathrm{R}}$ and (b) translational, $\mathrm{k}_{\mathrm{T}}$ spring stiffnesses.

Table 4: Connection model 2 spring stiffnesses. See Figs 3 and 4.

\begin{tabular}{|c|c|c|c|c|c|c|c|}
\hline \multirow[b]{2}{*}{ Spring } & \multirow[b]{2}{*}{ Type } & \multicolumn{2}{|l|}{$\mathbf{x} / \mathbf{x x}$} & \multicolumn{2}{|l|}{ y/yy } & \multicolumn{2}{|l|}{$\mathbf{z} / \mathbf{z z}$} \\
\hline & & $\begin{array}{l}\text { Linear/ } \\
\text { curve } \\
\text { ref. }\end{array}$ & $\begin{array}{l}\text { Stiffness } \\
(\mathbf{k N} / \mathbf{m}) \\
(\mathbf{k N m} / \\
\text { rad. })\end{array}$ & $\begin{array}{l}\text { Linear/ } \\
\text { curve } \\
\text { ref. }\end{array}$ & $\begin{array}{l}\text { Stiffness } \\
(\mathrm{kN} / \mathrm{m}) \\
(\mathrm{kNm} / \\
\text { rad. })\end{array}$ & $\begin{array}{l}\text { Linear/ } \\
\text { curve } \\
\text { ref. }\end{array}$ & $\begin{array}{l}\text { Stiffness } \\
(\mathbf{k N} / \mathbf{m}) \\
(\mathbf{k N m} / \\
\text { rad.) }\end{array}$ \\
\hline Property 1 & Translational & Linear & 1,4364 & Linear & 10,231 & Linear & 15,184 \\
\hline Property 2 & Rotational & Linear & 29.6 & Linear & 26.9 & Linear & 266.7 \\
\hline
\end{tabular}

3.3 Loading conditions and selected monitoring locations

Figure 5 shows the selected monitoring locations and Table 5 shows the defined load cases considered.

\section{ANALYSIS ASSUMPTIONS}

Importing the RSE dome model into the GSA environment automatically defined the nodes and their numbering. The element types and topology as well as the contraints and support conditions, required to be defined however.

The three property types used in GSA defined the $48.3 \mathrm{~mm}$ diameter $4.0 \mathrm{~mm}$ thick grade S355 CHSs and the 12 and $15 \mathrm{~mm}$ diameter grade M8.8 bolts of solid cross-section used for connecting the CHSs together in closed triangulated circuits. Two spring property types defined the translational and rotational stiffnesses.

The applied loading case LC3 output shown in Table 5 was used for monitoring comparisons [6].

\subsection{Linear elastic output}

The GSA linear elastic output results for the load range of $1 \mathrm{kN}$ to $8 \mathrm{kN}$ with varying boundary supports and connections models shown in Table 6 are now considered. 


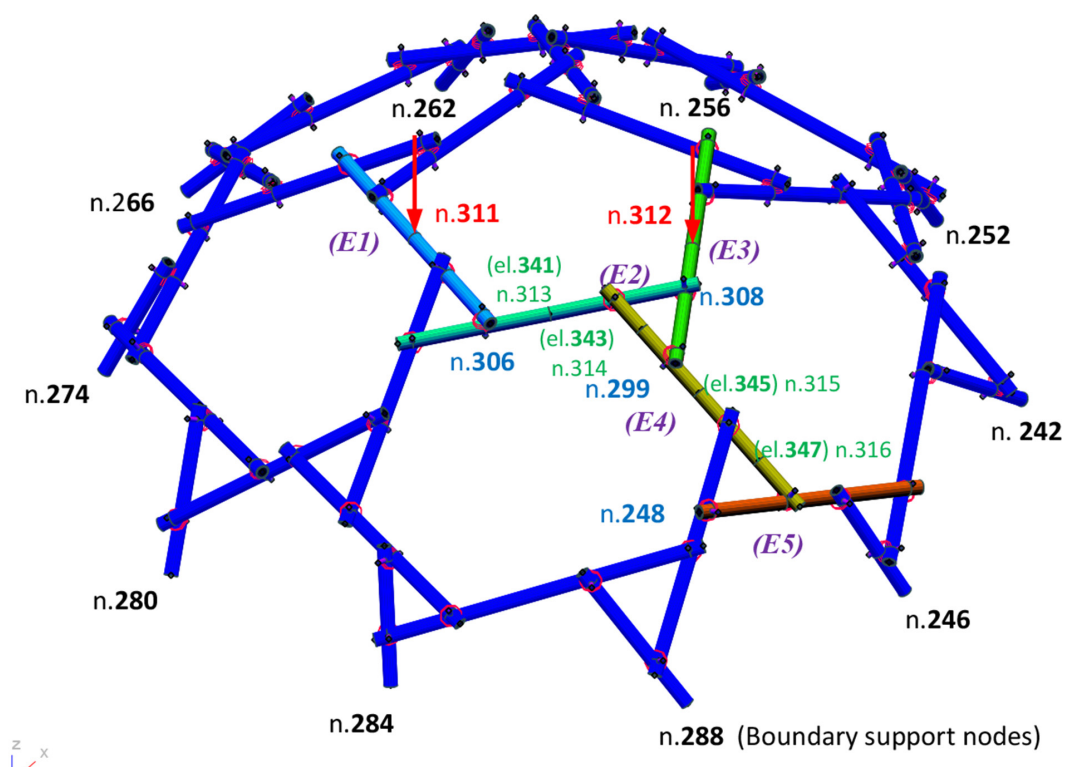

Figure 5: Perspective of RSE dome showing locations of eccentricity springs, boundary support nodes, applied loading, (n.311 and n.312), selected RSEs (E1 to E5) for monitoring displacements, (n.248, n.299, n.306, n.308), strains and stresses, (el.341, el.343, el. 345 and el.347).

Table 5: Defined load cases.

\begin{tabular}{lll}
\hline $\begin{array}{l}\text { Load } \\
\text { Case }\end{array}$ & Load Type & Description \\
\hline LC1 & $\begin{array}{l}\text { Permanent } \\
\text { Dead }\end{array}$ & $\begin{array}{l}\text { Self-weight of the dome structure composed of the CHS } \\
\text { tubes, saddleback washers with nuts and bolts only }\end{array}$ \\
LC2 & Permanent & $\begin{array}{l}\text { Self-weight of the anticipated loading beam plus load transfer } \\
\text { bearings applied at two locations }\end{array}$ \\
LC3 & Dead & $\begin{array}{l}\text { Applied load, up to a maximum total load of } 8 \mathrm{kN} \text {. Load to be } \\
\text { applied at two locations each with a maximum of } 4.0 \mathrm{kN} \text { and } \\
\text { applied in increments of } 0.5 \mathrm{kN}\end{array}$ \\
\hline
\end{tabular}

\subsubsection{Displacements}

The applied point load displacement graphs shown in Fig. 6 illustrate the predicted structural response of node $\mathrm{n} .308 . \mathrm{Mu}=1.0$ only is included in the displacement graphs for clarity. These can be seen to be linear elastic.

\subsubsection{Von Mises Stresses}

From the ductile material failure criterion, a simplified approach is used in GSA [7] to determine the von Mises stresses, $\sigma_{\mathrm{VM}}$, where: 
Table 6: Sample of RSE analysis dome models variations considered.

\begin{tabular}{|c|c|c|}
\hline Model & $\begin{array}{l}\text { Boundary } \\
\text { Supports }\end{array}$ & $\begin{array}{l}\text { Connection } \\
\text { Model }\end{array}$ \\
\hline i & All pinned & Model 1: Fixed \\
\hline ii & $\begin{array}{l}\text { Two pinned. Eight with horizontal spring } \\
\text { stiffnesses, kx \& ky and restrained in the } \\
\text { vertical z-direction. }\end{array}$ & Model 1: Fixed \\
\hline iii & $\begin{array}{l}\text { Two pinned. Eight with horizontal rollers } \\
\text { and restrained in the vertical z-direction. }\end{array}$ & Model 1: Fixed \\
\hline iv & $\begin{array}{l}\text { Two pinned. Eight with horizontal spring } \\
\text { stiffnesses, kx \& ky and restrained in the } \\
\text { vertical z-direction. }\end{array}$ & $\begin{array}{l}\text { Model 2: Translational and Rota- } \\
\text { tional spring stiffnesses, } \mathrm{k}_{\mathrm{T}} \& \mathrm{~K}_{\mathrm{R}}\end{array}$ \\
\hline $\mathbf{v}$ & All pinned & $\begin{array}{l}\text { Model 2: Translational and Rota- } \\
\text { tional spring stiffnesses, } \mathrm{k}_{\mathrm{T}} \& \mathrm{~K}_{\mathrm{R}}\end{array}$ \\
\hline
\end{tabular}

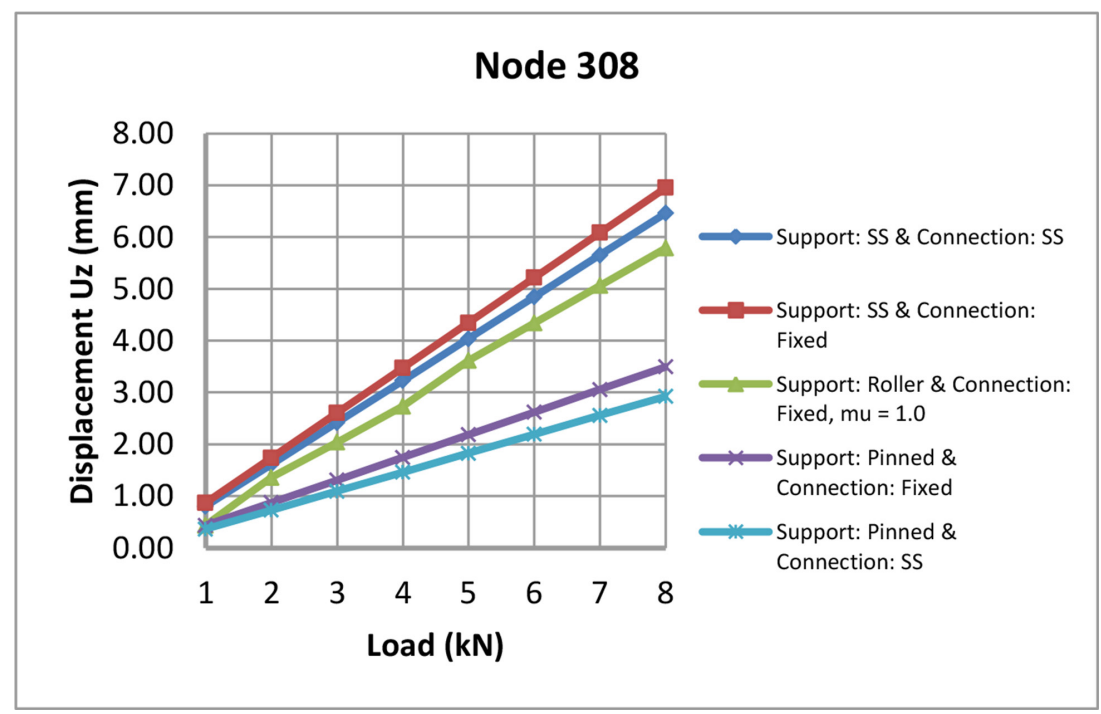

Figure 6: Predicted displacements of node 308. See Table 6 and Fig. 5 for node location.

$$
\sigma_{\mathrm{VM}}=\left(\sigma_{\mathrm{xx}}{ }^{2}+3 \tau_{\mathrm{xy}}{ }^{2}+3 \tau_{\mathrm{xz}}{ }^{2}\right)^{0.5} \leq \sigma_{\mathrm{y}} \text { (yield strength of material) }
$$

The Von Mises stresses are calculated in GSA assuming that the maximum through thickness stress and torsional stress coexist. These depend on combining the axial forces, $\mathrm{F}_{\mathrm{x}}$ the bending moments $\mathrm{M}_{\mathrm{yy}}$ and $\mathrm{M}_{\mathrm{zz}}$ to give $\sigma_{\mathrm{xx}}$ and the through thickness shear forces, $\mathrm{F}_{\mathrm{y}}$ and $\mathrm{F}_{\mathrm{z}}$ and the torsional moment, $\mathrm{M}_{\mathrm{xx}}$ to give $\tau$. In most cases, this is an over-estimate of the von Mises stress. Tensile stresses are taken as positive [7]. Fig. 7b shows the von Mises stresses distribution and Table 7 indicates the calculated values at the monitoring locations. 


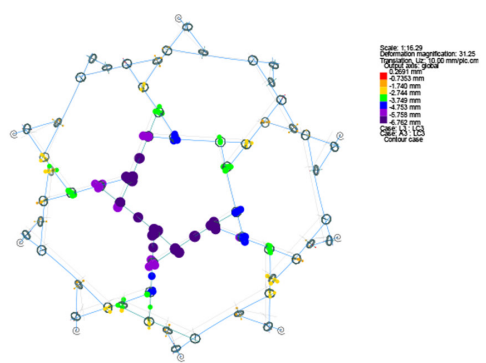

(a)

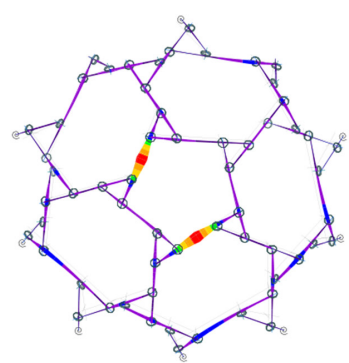

(b)

Figure 7: Dome plan, Table 6, model iv, at $8 \mathrm{kN}$ total applied loading (a) deflected shape and displacement, Uz, and (b) von Mises stresses, $\sigma_{\mathrm{vm}}$

Table 7: von Mises stresses, $\sigma_{\mathrm{vm}}$ under $8 \mathrm{kN}$ total applied loading. See Table 6 model iv and Fig. 5 for node locations.

\begin{tabular}{lllll}
\hline & \multicolumn{2}{l}{$\begin{array}{l}\text { Max. Elastic Shear } \\
\text { Stresses }\end{array}$} & $\begin{array}{l}\text { Torsional } \\
\text { Stresses }\end{array}$ & Von Mises \\
\hline Element, el. @ & SEy & SEz & St & $\sigma_{\mathrm{vm}}$ \\
(end node, n.) & $\left(\mathrm{N} / \mathrm{mm}^{2}\right)$ & $\left(\mathrm{N} / \mathrm{mm}^{2}\right)$ & $\left(\mathrm{N} / \mathrm{mm}^{2}\right)$ & $\left(\mathrm{N} / \mathrm{mm}^{2}\right)$ \\
el.341, (n.313) & 1.741 & -0.936 & -1.140 & 24.09 \\
el.343, (n.314) & 0.071 & 2.221 & 0.990 & 26.04 \\
el.345, (n.315) & 1.631 & -2.468 & 4.797 & 27.88 \\
el.347, (n.316) & -1.452 & -1.165 & 8.111 & 17.67 \\
\hline
\end{tabular}

\section{CONCLUSIONS}

To replicate the anticipated support conditions in the laboratory, a number of factors were investigated. A number of global linear elastic analysis models with variations in boundary supports in combination with two types of connection models were considered. Modelling of the anticipated boundary support conditions to determine lateral stiffnesses, potential for sliding under load, CHS bolted connection lateral and rotational stiffnesses, required that analysis in stages be carried out. The creation of finite element connection models were required to determine spring stiffnesses used in the dome global analysis models.

The predicted displacements at the selected monitoring locations under the applied loading were linear elastic. Unrealistic high values of Von Mises stresses were apparent in the bolts when analysis assumed full fixity between the bolts and CHS tubes. When two spring elements were assumed to represent the bolts, no Von Mises stresses were developed in the bolts. The applied loading was within the elastic range of the tube material according to the Von Mises yield criterion and the behaviour of the dome remained elastic.

\section{REFERENCES}

[1] Rizzuto, J.P., The structural behaviour of mutually supported elements in space structures. PhD theses, Coventry University, 2005.

[2] Baverel, O., Nexorades: A family of interwoven space structures. PhD theses, University of Surrey, 2000. 
[3] Nooshin, H. \& Disney, P., Formex configuration processing II. International Journal of Space Structures, 16(1), pp. 1-56, 2001. http://dx.doi.org/10.1260/0266351011495313

[4] Rhinoceros Training Manual v.4.0, Robert McNeal \& Associates, 2006.

[5] Rizzuto, J.P., Rotated mutually supported elements in truncated icosahedric domes. Journal of the International Association for Shell and Spatial Structures, 48(1), pp. 3-17, 2007.

[6] Rizzuto, J.P. \& Hulse, R., Dodecahedric mutually supported element space structure: experimental investigation. International Journal of Space Structures, 22(2), pp. 107-121, 2007.

http://dx.doi.org/10.1260/026635107781482640

[7] OASYS GSA Help Guide, GSA 8.7, London, England, 2016.

[8] Hannah, J. \& Hillier, M.J., Applied Mechanics, 3rd edn., Longman Scientific \& Technical, 1995.

[9] Rizzuto, J.P. \& Popovic Larsen, O., Connection systems in reciprocal frames and mutually supported elements space structure networks. International Journal of Space Structures, 25(4), pp. 243-256, 2010.

http://dx.doi.org/10.1260/0266-3511.25.4.243

[10] Rizzuto, J.P., Eccentricity orientation of bolted connections in space structure configurations using reciprocally supported elements. Journal of the International Association for Shell and Spatial Structures, 55(1), pp. 49-62, 2014.

[11] Rizzuto, J.P., Dodecahedric mutually supported element space structure: numerical modelling. Journal of the International Association for Shell and Spatial Structures, 49(1), pp. 3-18, 2008. 